\title{
Importance of Upper Airway Airflow in the Ventilatory Depression of Laryngeal Origin
}

\author{
JACOPO P. MORTOLA, ${ }^{(20)}$ SAAD AL-SHWAY, AND ANNA NOWORAJ \\ Department of Physiology, McGill University, Montreal, Quebec, Canada
}

\section{Summary}

Flows of air through the upper airway depress ventilation, particularly in newborns. This reflex response can be due to changes in upper airway pressure and/or upper airway airflow. In order to investigate the separate role of these two factors, we have studied four adult cats and three newborn kittens anaesthetized with pentobarbital. The animals were spontaneously breathing through a tracheostomy placed low in the neck. A second cannula located just below the larynx could be connected to a steady airflow source or to a pressurized jar. During the delivery of upper airway airflows, tidal volume, frequency and ventilation were decreased. When static pressures of values similar to those measured during the delivery of the airflows were applied, no depression of the ventilatory parameters was observed. We conclude that dynamic flow dependent factors are required for the ventilatory inhibition originating from the upper airways.

\section{Abbreviations}

\section{f, frequency}

$\dot{\mathrm{V}}_{\mathrm{E}}$, instantaneous minute ventilation

$V_{T}$, tidal volume

Steady airflows delivered though the upper airways depress respiration in anaesthetized animals $(2,7,10)$ and awake humans (11). This inhibition occurs even at physiologic flows, and is more marked in the newborn than in the adult (2).

Receptors located in the laryngeal area seem to be the most likely in promoting the reflex ventilatory inhibition. In fact, local anaesthesia of the laryngeal mucosa or bypassing of the larynx abolishes the response $(2,7)$. By recording from the peripheral cut end of the superior laryngeal nerve it has also been shown that receptors located in the laryngeal area can be activated by puffs of air in both adults $(6,14,15)$ and newborns $(16,17)$.

Whether the reflex is mediated by changes in upper airway airflow or upper airway pressure or both is presently unclear.

If the upper airway pressure was the important factor, it would imply that even static increases in pressure could promote the respiratory inhibition. For example, closure of the vocal cords during expiration, a common phenomenon during the first hours of life in animals $(4,8)$ and infants $(5)$ may prolong expiration not only through the pulmonary vagal feedback but also through the laryngeal afferents. On the other hand, if the airflow through the upper airways was the essential factor, the respiratory inhibition of laryngeal origin can be expected to occur only in dynamic conditions. A flow sensitivity of the upper airway receptors has been suggested $(1,2,11)$ but not documented.

In this study we consider separately the role of upper airway pressure and airflow, in an attempt to separate the role of static and dynamic stimuli in the ventilatory inhibition of laryngeal origin.

\section{MATERIALS AND METHODS}

Experiments were done on three kittens (age, $1.2 \pm 0.6$ days S.D. and weight, $124 \pm 7$ g S.D.) and four adult cats (weight, 2.0 $\pm 0.25 \mathrm{~kg} \mathrm{S.D.)}$. The animals were anaesthetized with sodium pentobarbital (initial dose, $25-35 \mathrm{mg} / \mathrm{kg}$ I.P.) and were placed in the supine position with the head moderately extended. The experimental set-up is similar to what has been previously described (2). Respiratory flow of the spontaneously breathing animal was measured with a pneumotachograph connected to a tracheal cannula placed in the lower portion of the extrathoracic trachea and coupled to a differential pressure transducer (Hewlett Packard model 270). Tidal volume was obtained by integration of the airflow signal. In the newborn the pneumotachograph consisted of a small cannula (internal diameter, $1.7 \mathrm{~mm}$ and length, $25.6 \mathrm{~mm}$ ) with two side arms connected to a differential pressure transducer (Hewlett Packard model 270). The pneumotachograph was tested in the following way. It was connected to a ventilator, which provided oscillatory flows into a sealed box; the pressure in the box and the differential pressure of the pneumotachograph were simultaneously recorded and displayed on an X-Y storage oscilloscope. No loops were observed up to a frequency of 70 cycles/min. The linearity of the flow signal was also checked up to flows of $20 \mathrm{ml} \cdot \mathrm{sec}^{-1}$. In the adult a Fleish pneumotachograph (No. 00) has been used. A second cannula was inserted just below the cricoid cartilage and connected through a stopcock either to an airflow source or to a pressurized jar. In the first case, by turning the stopcock, flows could be delivered in a squared wave fashion through the larynx and the upper airways in the expiratory direction. Airflows of $50 \mathrm{ml} \cdot \mathrm{sec}^{-1} \cdot \mathrm{kg}^{-1}$, which approximately correspond to the mean flows occurring during hyperventilation, at room temperature and relative humidity (about $21^{\circ} \mathrm{C}$ and $60 \%$ respectively) were measured with a pneumotachograph coupled to a differential pressure transducer Hewlett-Packard model 270. The pneumotachograph was placed between the laryngeal cannula and the airflow source. The flow was maintained for the duration of 3 control breaths. A side arm of the sublaryngeal cannula was connected to a pressure transducer (Statham model PM5ETC) for measurements of upper airway pressure during the delivery of the flow.

Subsequently, in order to study the ventilatory effects of static upper airway pressure, the sublaryngeal cannula was connected through a stopcock to a pressurized jar. The pressure in the jar was, in each animal, similar to that previously measured in the upper airways during the delivery of the airflows. After manual closure of mouth and nostrils, at least five control breaths were recorded, then the pressure was applied by turning the stopcock and it was maintained for the duration of three control breaths.

Rectal temperature was measured with a thermometer and was maintained between $36-38^{\circ} \mathrm{C}$ by adjusting the distance of a heating lamp from the animal. The respiratory airflow and volume signals of the spontaneously breathing animal together with the upper airway airflow and pressure signals were simultaneously recorded on a multichannel Gould Brush pen recorder (model 260). 

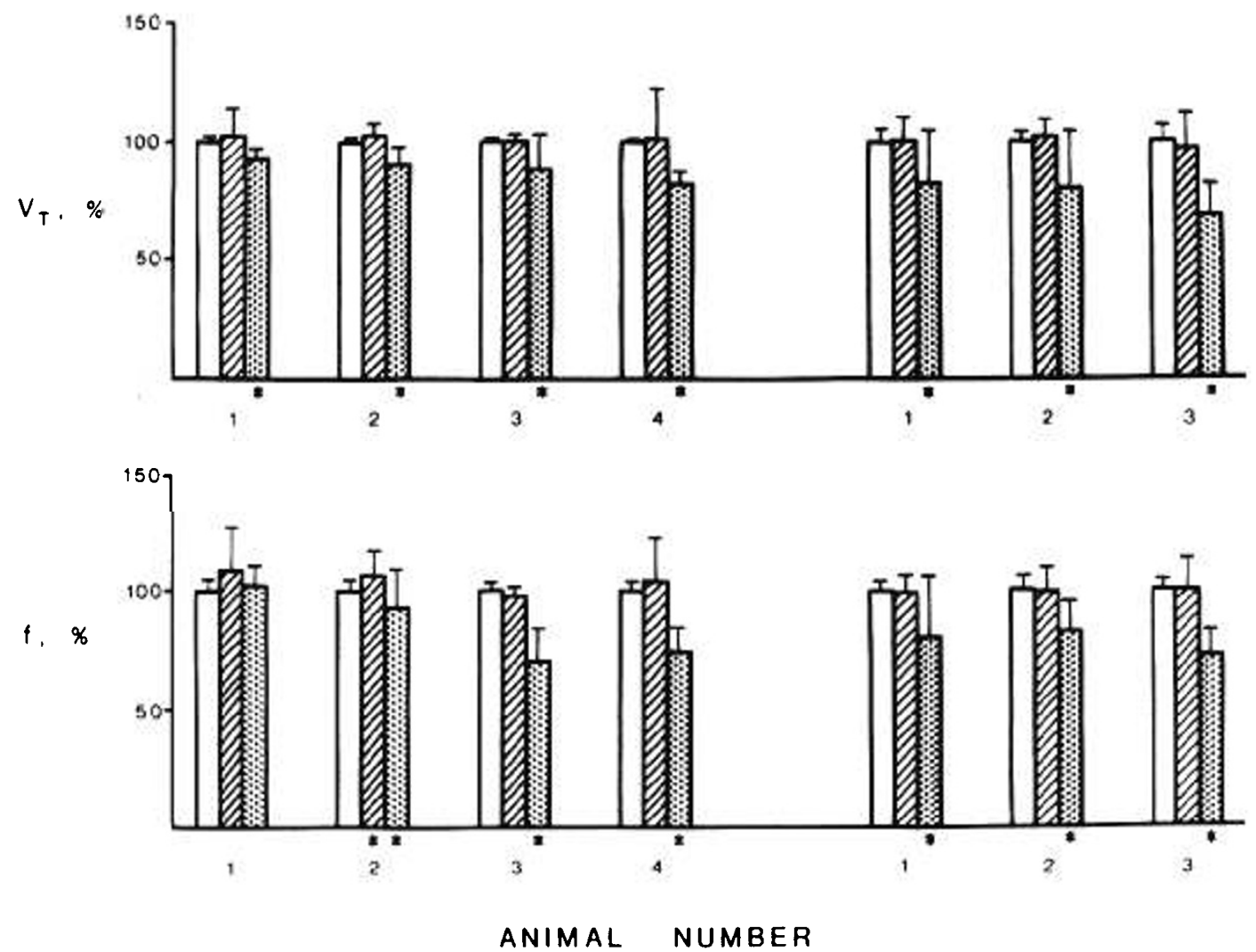

Fig. 1. Variations in tidal volume ( $\left.\mathrm{V}_{\mathrm{T}}, t o p\right)$ and respiratory frequency (f, bottom) during control trials (open columns), application of static upper airway pressures (dashed columns) and delivery of upper airway airflows (dotted columns). In each animal the values are expressed as \% of the mean of the control trials. Bars are standard deviations. Asterisks indicate a significant difference from the control trials (two tailed $t$ test, $\mathrm{t}<0.05$ ).

In each animal, 10 trials with upper airway airflows and 10 trials with upper airway pressures were performed. The spirometric variables (tidal volume, breathing rate and minute ventilation) of the three breaths immediately preceding and during the application of the upper airway stimulus (airflow or pressure) were analyzed.

To assess any random variation in the breathing pattern, in each animal a similar number of "control trials" was performed: any three breaths were compared with a following interval of equal duration but with no stimulus (2). Measurements were obtained both in absolute terms and as \% of the mean values of the preceding control breaths. A paired $t$ test analysis has been used to determine a significant difference (level of significance for two-tailed test $<0.05$ ) between any spirometric value during control trials and the corresponding value during the delivery of the airflow or the application of the pressure.

\section{RESULTS}

When steady airflows were delivered through the upper airways, tidal volume $\left(V_{T}\right)$ decreased significantly in all the seven animals, and frequency (f) dropped significantly in six of them, relatively to the control trials (Fig. 1).

On the contrary, when the upper airways were connected to a static pressure the value of which was similar to that measured during the delivery of the airflow, in no case was a depression of $V_{T}$ or $f$ observed. With the exception of cat \#2 (in which a slight increase in $f$ was recorded), in all the other instances both $V_{T}$ and $f$ remained similar to the values measured during the control trials (Fig. 1).

As can be predicted from the above results, the instantaneous minute ventilation $\left(\dot{\mathrm{V}}_{\mathbf{E}}\right)$ was significantly depressed with respect to the control trials during the delivery of the upper airway airflows. The drop was significant in three of the four cats and in all the kittens. On the contrary, in both cats and kittens no significant changes in ventilation occurred when static pressures were applied.

\section{DISCUSSION}

The present results indicate that the upper airway pressure per $s e$ is not responsible for the ventilatory depression of laryngeal origin. On the contrary, they strongly support the idea that the upper airway airflow may be the relevant parameter, on line with some previous suggestions $(2,6)$.

The airflow dependence of the upper airway ventilatory inhibition does not rule out the possibility that other factors could play a role in the activation of the upper airway receptors responsible for this reflex. Even though the ventilatory inhibition was previously found to be marked also with the delivery of $37^{\circ} \mathrm{C}$ humidified airstreams (2) it cannot be excluded that the temperature in the receptors' microenvironment may fall below the normal value. In adult cats the optimal firing rate of the superior laryngeal nerve afferents was found to be at temperatures between $25-32^{\circ} \mathrm{C}$ (14).

The possibility that the receptors are mainly sensing the variation in tension rather than its static value, as postulated for the pulmonary mechanoreceptors (12), should also be considered. In fact, unlike the static condition, a substantial distortion of the upper airways during the delivery of steady airflows can occur (13) and may lead to continuous changes in tension at the receptors' level.

In conclusion, although it is presently unclear whether a mechanical or thermal stimulus is the most appropriate, it seems 
certain that a dynamic event is the important trigger of the reflex ventilatory response originating from the upper airways. Similarly, in adult rabbits it has been recently shown that the maintenance of upper airway patency depends upon sensory stimuli promoted by upper airway airflows rather than statically applied pressures (1).

The ventilatory control of laryngeal afferents may play a relevant role during conditions of zero flow periods, as a protective mechanism which favors inspiration. In fact, because of the reflex effects on ventilation of these upper airway airflows is inhibitory, any situation tending to decrease the airflows, either on a peripheral or central basis, will ultimately favor inspiratory activity. In this respect, it may not be coincidental that this reflex, as others of laryngeal origin promoted by chemical substances $(3,9,18)$, is more pronounced in the newborn where apnea is a common event.

\section{REFERENCES AND NOTES}

Abu-Osba, Y. K, Mathew, O. P and Thach, B. T. An animal model for airway sensory deprivation producing obstructive apnea with postmortem findings of Sudden Infant Death Syndrome. Pediatrics, 68: 796 (1981).

2. Al-Shway, S. and Mortola, J. P.: Respiratory effects of airflow through the upper airways in newborn kittens and puppies. J. Appl. Physiol.: Respir. Environ. Exercise Physiol., 53: 805 (1982).

3. Downing, S. E. and Lee, J. C.: Laryngeal chemosensitivity: a possible mechanism for sudden infant death. Pediatrics, 55: 640 (1975).

4. Farber, J. P.: Laryngeal effects and respiration in the suckling oppossum. Respir Physiol., 35: 189 (1978).

5. Fisher, J. T., Mortola, J. P., Smith, J. B., Fox, G. A., and Weeks, S.: Respiration in newborns. Development of the control of breathing. Am. Rev. Respir. Dis. 125: 650 (1982)

6. Frankenhaeuser, B.: Sensory impulses in large nerve fibers from the epiglottis of the rabbit. Acta Physiol. Scand. Suppl., 53: 24 (1948).

Copyright $(\mathcal{C} 1983$ International Pediatric Research Foundation, Inc. $0031-3998 / 83 / 1707-0550 \$ 02.00 / 0$
7. Hammouda, M. and W. H. Wilson. Influences which affect the form of the respiratory cycle, in particular that of the expiratory phase. J. Physiol. (London), 80: 261 (1933)

8. Harding, R., Johnson, P., and McCleuand, M. E.: Respiratory function of the larynx in developing sheep and the influence of sleep state. Respir. Physiol., 40: 165 (1980).

9. Johnson, P.: Laryngeal Induced Apnea. SIDS 1974: Proceedings of the Francis E. Camps Symposium, edited by R. R. Robinson, Canadian Foundation for the Study of Infant Deaths, Toronto, 231-242.

10. Lumsden, T.: The regulation of respiration. Part II. J. Physiol. (London), 58: 11 (1923).

11. McBride, B and Whitelaw, W. A.: A physiological stimulus to upper airway receptors in humans. J. Appl. Physiol.: Respir. Environ. Exercise Physiol., 51: 1189 (1981).

12. Mortola, J. P. and Mortola, S. A.: Tracheal slowly adapting stretch receptors: theoretical models. J. Theor. Biol., 83: 313 (1980).

13. Mortola, J. P. and Fisher, J. T.: Mouth and nose resistance in newborn kittens and puppies. J. Appl. Physiol., 51: 641 (1981).

14. Sampson, S. and Eyzaguirre, C.: Some functional characteristics of mechanoreceptors in the larynx of the cat. J. Neurophysiol., 27: 464 (1964).

15. Storey, A. T.: A functional analysis of sensory units innervating epiglottis and larynx. Exp. Neurol., 20: 366 (1968).

16. Storey, A. T. and Johnson, P.: Laryngeal water receptors initiating apnea in lambs. Exp. Neurol., 47: 42 (1975).

17. Storey, A. T. and Johnson, P.: Laryngeal receptors initiating apnea in lambs. In: Development of Upper Respiratory Anatomy and Function, edited by Bosma and Showacre, U.S. Government Printing Office, Washington, D.C., 184 (1975).

18. Tchobroutsky, C., Merlet, C., and Rey, P.: The diving reflex in rabbit, sheep and newborn lamb and its afferent pathways. Respir. Physiol., 8: 108 (1969).

19. This study was supported by the Medical Research Council of Canada and Sick Children's Hospital Foundation, Toronto. We wish to thank Mrs. Christine Pamplin and Mrs. Sandra James for typing the manuscript.

20. Requests for reprints should be addressed to: Dr. Jacopo P. Mortola, Departmen of Physiology, McGill University, 3655 Drummond Street, Montreal, Quebec H3G 1Y6, Canada.

21. Received for publication May 4, 1982

22. Accepted for publication November 12, 1982 